\title{
PUZZLES OF THE PAST The way we were and the way we are going
}

TIM T. TOKARYK, Royal Saskatchewan Museum, Wascana Park, Regina, Saskatchewan. S4P 3V7

I have had the good fortune to discover and work on a few fossils that have received some attention from the media. Many people, including scientists, shy away from this attention and personally I could do without acting as the fossils' interpreter. Yet I feel strongly that public attention is useful for the museum scientist and feel obligated to work with the media. In the museum's ongoing activity any publicity says, at least, that this institution is not a static place. Still, in this era of "dinomania" I can not help but wonder if scientists, more specifically paleontologists, have failed in education of the public. Case in point - the most often asked question from the media I have experienced is "So, what does this new discovery mean to Joe Public?" This question not only reflects the ignorance of the public about why we do what we do, but ultimately the lack of concern scientists show towards the public in regards to education.

To fully appreciate any answer I may give, some understanding of the history of the science is required, even if it is brief. You will note in the following paragraphs that I give fossils, paleontology, and evolution the same general meaning. Evolution, like many other sciences, is dependent or proportionally enhanced by paleontology, which in turn is solely responsible for interpreting the fossils. The growth of evolutionary thinking follows this same pathway to a certain degree [I am not a great believer in linear thinking; life and history are too complex, but at least in this case it will do].

Historically, paleontology emerged from gentlemanly inquiry to stand on its own as an actual scientific adventure. Prior to Charles Lyell and his contemporaries in the 19th century, when scientists' work covered many disciplines, fossils held a more questionable status. It was first thought that fossils were "sports of nature," abnormalities produced in the rocks naturally. Nicholas Steno (16381687) thought differently. In Florence, he dissected the head of a large shark recently caught. $\mathrm{He}$ found great similarity between the teeth of modern sharks and those "tongue stones" of the past - teeth found in sedimentary rocks. Through a combination of biological and geological reasoning Steno convincingly suggested that the fossils were organic remains of the past and not inorganic "sports." 
This suggestion was taken further by a contemporary of Steno, Robert Hooke (1635-1703). The idea of extinction of a species in the non-biblical sense was new. As Sir Charles Lyell pointed out in his Principles of Geology (three volumes published between 1830-1833) "In some parts of his writings ... [Hooke] leans to the opinion that species had been lost ... that there might be some connection between the disappearance of certain kinds of animals and plants and changes wrought by earthquakes in former ages" (p. 32). ${ }^{4}$ The important point here is that Hooke thought that extinction of certain species was caused by earthly events and not by a global catastrophe of heavenly causes like the biblical flood. Suspicious of naturalists' parochial knowledge of things that swim, crawl, walk and fly, Hooke gave strength to the belief that more examples of nature were needed.

There is a quote of Hooke that Lyell recounts that deserves repeating: "However a trivial thing a rotton [sic] shell may appear to some, yet these monuments of nature are more certain tokens of antiquity than coins or medals, since the best of those can be counterfeited or made by art and design ... and though it must be granted that it is very difficult to read them (the records of the past) and to raise a chronology out of them, and to state the intervals of the time wherein such or such catastrophes and mutations have happened, yet it is not impossible" (p. 32). ${ }^{4}$ Hooke signals that there are many questions yet to be posed as well as possible answers.

Evolution was in the air in the early and mid-19th century, before Darwin. Yet the proposed mechanisms of the process were unconvincing to all concerned. The Frenchman JeanBaptiste Lamarck

(1744-1829) received some attention for attempting to popularize the idea of enhancement or atrophy of organs by means of use or disuse - the famous example of the giraffe stretching its neck further to obtain more food. During Lamark's time Darwin's grandfather Erasmus (1731-1802) even had some rudimentary concepts of evolution. Adrian Desmond has written an exhaustive account of pre-Origin of Species thinking with respect to the social atmosphere in Politics of Evolution. ${ }^{1}$ During the 1820 s and 1830 s "all sorts of dissident knowledge flourished: not only varieties of evolution, but a swirling vortex of alternative economics, social, and biological sciences that threatened to wash away the pillars of the establishment edifice. Unlike the gentlemen's polished, expensive treatises, these sciences were spread through radical medical newspapers and inflammatory penny prints" (p. 4). ${ }^{1}$ Radical thinking was the bed in which evolution was conceived and eventually received. The culmination of this thinking brought fossils out from the depths of ignorance to eventually support a tangible proposal that sheds some light on our existence and our surroundings and how it all came to be. And through the pages of magazines and newspapers the public was well informed.

The story doesn't end there. David Lull compiled several critical reviews of Darwin's book at the time of its publication. ${ }^{3}$ By examining this collection it isn't hard to see that "Evolutionary theory seems capable of offending almost everyone" (p. 7). ${ }^{3}$ Many of these original critiques were published in technical journals yet some were published for all to see in the more popular press of their time: William Hopkins published his review in Fraser's Magazine; Louis Agassiz 
in The Atlantic Monthly; Henry Fawcett in Macmillan's Magazine; Adam Sedgwick in The Spectator, and Joseph Hooker in Gardener's Chronicle. The public knew at least that something was up.

Eventually most opposition was quelled by further exploration for fossils and additional development of evolutionary theory, but it was a rough road. Fossils were a particular concern for Darwin because of the missing gaps in the record. Two years after the publication of Origin of Species some of Darwin's fears were lessened as the lithographic limestone in Germany yielded the oldest bird skeleton known Archaeopteryx. What made this bird so spectacular was that it had characteristics of its reptilian ancestry, most obviously a tail and teeth. It was a missing link of sorts and future discoveries of fossils were held as evidence for Darwinian evolution.

For the most part this parleying of information by paleontologists to the public diminished around the turn of the century. The one notable exception was in popularizing the evolutionary history of Homo sapiens. The impact of Darwin's thesis ultimately shook (and in some quarters still does) the vanity of our species. Any new discovery of a proto-human still rings the bell for media editors. For the rest of the paleontological community, those of us who work on lesser players in the evolutionary field make less of an impact unless the new discovery is of some unheard-of titan.

In 1911, W.D. Matthew (18701930), then curator at the American Museum of Natural History in New York, viewed paleontology in the modern museum (which was relatively a recent development in North
America) as "documents ... [showing the] larger history which traces the orderly development of life through vast periods of geological time." $\mathrm{Mu}$ seums became the medium through which scientists could translate their ideas to the public but at the same time the paleontologists became invisible, or at least had the option of hiding behind the displays. In 1910, W.J. Sinclair of Princeton University saw paleontology resolving lesser questions related to the science like stratigraphy. ${ }^{6}$

The direction of paleontology is still unfolding. Today, paleontology as a whole owes a lot to the extinction of dinosaurs (like it or not) if for only resurrecting the stony skeletons and putting their names back in the news. The cause of this resurrection has not been due to mere rediscovery of dinosaurs and paleontology by the public, but because new ideas, supported by some physical evidence reveal a dramatic, more realistic story: the intelligent carnosaur hunting down its prey, the protective mother dinosaur feeding her young. Visually this is translated in books, magazines, movies and museums. Funding for exhibits either revamped or newly developed - has grown at an enormous rate in North America over the past two decades. Almost every major museum has changed somewhat to accommodate the public's new interest. The popularity reached its zenith with Steven Spielberg's Jurassic Park. Yet, conversely, paleontology as a science is barely keeping its head above water or in some cases is slowly drowning.

The problem is this: the idea that research has to yield a real, tangible and commercial gain is sentencing the historical sciences like paleontology to the basement (in some 
institutions it's the boiler room in the basement). Princeton (which played a major role in the early development of paleontology in North America) axed its vertebrate paleontology program in the mid-1980s, its collections given to Yale. Museums like the ones in San Diego and London cut the support for paleontology drastically. Museum administrators, seeing the commercial excitement over what's vogue (like dinosaurs) have developed a new philosophy. Some call it the Disneyland approach to museums which in essence means spend less on research (which in many cases not only cuts operating budgets but staff as well) and hand over the museum's directional reins to exhibits. The scientists are trying to secure some ground but the power is usually not in their hands.

Stephen Gould had this warning for us when he reviewed the book and movie Jurassic Park. ${ }^{2}$ The pursuit of commercial gain or at least sustenance from commercial gain like those incorporated in theme parks (which have little if any regard to education) "will swallow museums if educators try to copy the norms of business for immediate financial gain" (p. 56). ${ }^{2}$ Short-term gains in the evolutionary sense and the economic sense often lead to extinction.

Why do we still collect fossils? There are still many evolutionary questions that we have only tentative or obscure answers for - extinction, both global and regional throughout the geological column and evolution of major taxonomic groups as well as specific groups. Fossils that surprise us by turning up in places and geological strata previously never thought probable, and the continuing reconstruction of paleoenvironments have and will continue to shape our ideas about current and future bio- tas. To answer the reporter's question "What does this new discovery mean to Joe Public?" - in the spirit I believe the question is intended, my reply is, "Nothing." The paleontologist has no direct impact on the many social or economic ills we endure today. The paleontologist is a story teller and the book he or she uses is incomplete, missing a few chapters, some pages, many paragraphs and sentences. Yet, each year we spend what little funds are available to us to scour the valleys, hillsides and mountains to fill in some of the gaps. If we were to read the book of the earth without the past, some 4.5 billion years, there would be no meaning to it. A true perspective of today and tomorrow includes examining yesterday.

Our attitudes towards science and the men and women who are fortunate to perform such often uncelebrated tasks are continually changing. Today it is expected that financial rewards are the gauges of scientific success. If this perception were cemented entirely into the philosophy of scientific pursuit the historical sciences like paleontology would shrivel up and die. Yet there is something about paleontology that attracted me and I suppose many others to this field - simple curiosity. It is the same ethereal curiosity that I see in the eyes of school children who want to know what was the biggest dinosaur or how mean was Tyrannosaurus rex. It is often a child's first exploration into science. Unfortunately, paleontology like many other sciences is involuntarily tied up in the straitjacket of project objectives, financial gain and all of the other trappings of today. To try and gain some perspective on the simple questions that we and our ancestors have asked - where do we come from and why? - is in my eyes a very noble and worthwhile 
pursuit that needs no hardened, black or white answer or justification. It would be a sad loss if paleontology went the way of the dinosaur.

1. DESMOND, A. 1989. The Politics of evolution. University of Chicago Press, Chicago. 503 pp.

2. GOULD, S.J. 1993. Dinomania. The New York Review of Books 40 (14):51-56.

3. LULL, D.L. 1973. Darwin and his critics. University of Chicago Press, Chicago. 473 pp.

4. LYELL, C. 1990. Principles of geology, volume 1, (first published in 1830 by John Murray, London). University of Chicago Press, Chicago. 511 pp.

5. MATTHEW, W.D. 1911. Fossil vertebrates - what they teach. American Museum Journal 11:246-247.

6. SINCLAIR, W.J. 1910. Interdependence of stratigraphy and paleontology. Popular Science Monthly June: 589591.

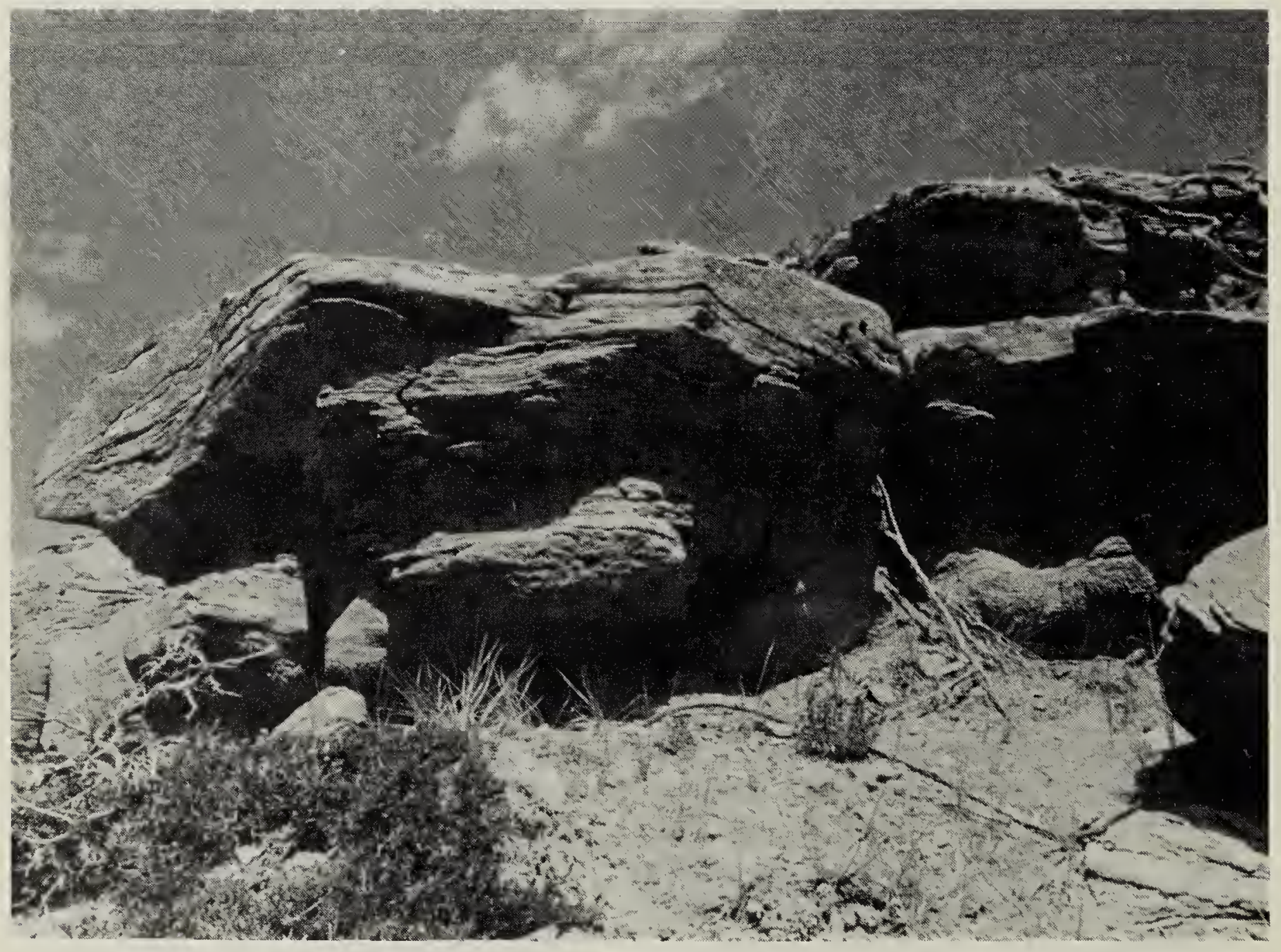

